\title{
Passenger exposure to aerosols on intra-European train travel
}

\author{
Patrik Winiger ${ }^{1,2}$ (1)
}

Received: 14 October 2020 / Accepted: 1 December 2021 / Published online: 12 January 2022

(c) The Author(s) 2022

\begin{abstract}
Knowledge about personal aerosol exposure in different environments is fundamental for individual and common decisionmaking, shaping the way we build our infrastructure or change our social behaviours. Aerosols are a leading cause of death and well-known vector for infectious diseases. Yet, passenger exposure to aerosols during long-distance train travel is surprisingly underexplored. Two small, light-weight personal monitoring instruments were employed during a train journey across Europe, to measure the fine particle $\left(\mathrm{PM}_{2.5}\right)$ and equivalent black carbon (eBC) passenger exposure, respectively. The journey was divided into three legs, inside three different trains, and two layovers in city environments. Highest mean concentrations of $\mathrm{PM}_{2.5}$ and $\mathrm{eBC}$ were found within the oldest train type, and revealed $\mathrm{PM}_{2.5}$ concentrations of $58.4 \pm 12.7 \mu \mathrm{g} \mathrm{m}^{-3}$ and $\mathrm{eBC}$ of $5.4 \pm 2.9 \mu \mathrm{g} \mathrm{m}^{-3}$. The more modern the train system was, the lower the measured concentrations were to be found. In the newest tested system, the air quality was considerably better inside the train than outdoor air measured by a monitoring network, or simulated by the Copernicus Atmosphere Monitoring Service (CAMS) model ensemble analysis. The mean $\mathrm{PM}_{2.5}$ concentration was roughly $20 \%$ lower inside the train than the outdoor air simulated by CAMS. Both the light-weight personal monitoring and the monitoring network indicate that the CAMS ensemble substantially underestimates $\mathrm{PM}_{2.5}$ concentrations for the day of the journey. Effective ventilation and air filtration significantly decrease the passenger's aerosol exposure, as compared to a stay in outdoor air, leading to a small statistical increase in life expectancy. If this could also reduce the risk of contagion with an infectious disease remains to be explored.
\end{abstract}

Keywords Air quality $\cdot$ Fine particles $\cdot$ Black carbon $\cdot$ Passenger exposure

\section{Introduction}

High mobility and a carbon footprint in line with the Paris $1.5^{\circ} \mathrm{C}$ target remain in conflict with each other. Air and land transport are the number one cause of greenhouse gas (by $\mathrm{CO}_{2}$ equivalent) emissions among the top $1 \%$ EU households, which are defined as having an annual net income of $>€ 40,000$ per person (Ivanova and Wood 2020). As long as mobility remains a desire of our society and its most affluent elements, more sustainable ways of transport must be sought. Renewable energy-powered high-speed trains are undoubtedly the most sustainable mode of (mass) transport,

Patrik Winiger

patrikwiniger4@gmail.com

1 Earth and Climate Cluster, Faculty of Earth and Life Sciences, VU University Amsterdam, Amsterdam, the Netherlands

2 ETH Zürich, Zürich, Switzerland currently available. Yet little is known about the quality of air inside intra-European or long-distance trains in general.

This is relevant for two reasons: (1) air pollution from aerosols is a leading cause of death (Lelieveld et al. 2020) and (2) being in close proximity to other humans inside narrow spaces for prolonged periods of time bears additional risks, like the spread of infectious diseases via aerosols (Morawska et al. 2020; Prather et al. 2020). Knowledge about potential exposure to aerosols in train carriages is a factor which passengers will likely consider in their decision-making, if there are alternative means of transport.

In this study, concentrations of particulate matter smaller than $2.5 \mu \mathrm{m}\left(\mathrm{PM}_{2.5}\right)$ and equivalent black carbon (eBC), particles of incomplete combustion, were observed with two small, light-weight personal monitoring instruments during an $\sim 8.5 \mathrm{~h}$ journey from Zürich, Switzerland, to Amsterdam, The Netherlands. Similar work has been performed in different micro-environments or commuting environments around the world (Karanasiou et al. 2014; Kaur et al. 2007), but never in long-distance or international trains. Very few 
studies exist with observations during relatively longer (1-2 h) journeys (Abadie et al. 2004; Fridell et al. 2011; Leutwyler et al. 2002), of which two were measured in an era where smoking was still allowed on trains (Abadie et al. 2004; Leutwyler et al. 2002). Studies with passenger carriages are often conducted in local city underground networks (Cheng et al. 2012; Johansson and Johansson 2003; Kam et al. 2011; Li et al. 2007; Smith et al. 2020; Van Ryswyk et al. 2017; Vilcassim et al. 2014) or local overground micro-environments (Dons et al. 2012; Hasenfratz et al. 2014; Morales Betancourt et al. 2017; Ragettli et al. 2013; Yang et al. 2015).

A systematic review of passenger exposure during shortdistance micro-environment commute found that, compared to pedestrians and cyclists, the most exposed people are passengers in cars without ventilation settings, followed by busses, motorcycles, cars with ventilation, and finally local train and subway systems (Cepeda et al. 2017). When physical activity was considered, the review authors found that passengers of motorised transport lose, statistically, up to 1 year of life expectancy compared to cyclists. Knowledge about air pollution exposure of long-distance train travelers will be an addition to future assessments of exposure studies, and can guide personal and common decision-making.

\section{Material and methods}

\section{Experimental settings}

Air quality measurements were conducted on a train commute from Zürich, Switzerland, to Amsterdam, The Netherlands, on Wednesday the $23^{\text {rd }}$ January 2019 (Table 1). Thanks to the German Railways' (DB) high-speed rail system with its Intercity-Express (ICE) trains, the $840 \mathrm{~km}$ distance is overcome in about $8.5 \mathrm{~h}$.

Each of the two light-weight instruments (described in more detail in the following section) was placed inside one of the two stretch-woven pockets on the outside of a backpack. The backpack was stored in the open overhead compartment on each of the three trains connecting Zürich and

Table 1 Train connection details according to the timetable. No major delays or other mutations were experienced

\begin{tabular}{lllll}
\hline Train stop & Date & Time & Platform & Train ID \\
\hline Zürich HB & 23.01 .2019 & $15: 00$ (dep.) & 16 & IC 776 \\
Basel SBB & 23.01 .2019 & $15: 53$ (arr.) & 5 & (IC) \\
Basel SBB & 23.01 .2019 & $16: 13$ (dep.) & 6 & ICE 274 \\
Frankfurt (Main) Hbf & 23.01 .2019 & $19: 08$ (arr.) & 9 & (ICE 1) \\
Frankfurt (Main) Hbf & 23.01 .2019 & $19: 29$ (dep.) & 19 & ICE 120 \\
Amsterdam Centraal & 23.01 .2019 & $23: 28$ (arr.) & $5 a$ & (ICE 3) \\
\hline
\end{tabular}

Amsterdam. In this manner, the instruments were not placed in the direct airflow of the train's air conditioning (aeration) system, yet the inlet faced towards the cabin centre. It is fair to assume enough turbulence within a passenger carriage that aerosol concentrations are evenly distributed. Differences might exist among carriages of the same train composition, due to varying types of deployed carriages and the performance of their aeration system. The Swiss Federal Railways (SBB) and DB feature both 1st and 2nd class seats. The instruments were placed in the 2 nd class, which transports more people per train and carriage. All trains were electricity-powered.

The first train, Intercity IC 776, was operated and owned by SBB and the instrument was placed inside a relatively old carriage (type Z2, carriage ID 2173), built between 1972 and 1978. These carriages are all one open space with 80 seats, grouped into units of four (two seats facing each other, 'Vis-à-Vis') on each side of the carriage. Within this relatively small volume with noticeable turbulence, it is safe to assume that all passengers are exposed to the same aerosol concentrations.

The second train was an ICE 274 operated and owned by $\mathrm{DB}$, on route Basel-Berlin. This train is a first-generation ICE 1 (five other variants exist today: ICE 2, ICE 3, ICE T, ICE TD, ICE 4), built between 1988 and 1993, with a max. speed of $280 \mathrm{~km} \mathrm{~h}^{-1}$. The seats inside the chosen carriage are a mixture of compartments with six seats ( 24 seats total) and open space seating with single seats, rows by two, and 'Vis-à-Vis' (50 seats total). The instruments were placed in the open space seating. The air quality in the compartments of six, which can be closed by sliding door, can be expected to vary significantly and would not be representative of the overall carriage air quality.

The last train was an ICE 120, operated by DB as well, on route Frankfurt-Amsterdam. This third-generation ICE 3 was built between 1997 and 2012, with a maximum speed of $330 \mathrm{~km} \mathrm{~h}^{-1}$ (in operation up to $300 \mathrm{~km} \mathrm{~h}^{-1}$ in Germany, and $320 \mathrm{~km} \mathrm{~h}^{-1}$ in France). Various 2nd class carriages exist, with 52, 54, 64, and 72 seats. The instruments were placed in an open space seating featuring 72 seats total.

The instruments were switched on upon boarding the train in Zürich, and were only switched off for a couple of minutes (inside the connecting train) in Basel, to check if data retrieval was in order. The final minutes of data collection were recorded during a short walk from the Amsterdam central station through the Eastern inner city.

\section{Scattering}

A personal aerosol monitor, the TSI SidePak ${ }^{\mathrm{TM}}$ AM520 Optical Particle Counter, was used to measure $\mathrm{PM}_{2.5}$ particle concentration. The AM520 uses $90^{\circ}$ light scattering of a $650-\mathrm{nm}$ laser diode and is factory-calibrated against a 
gravimetric reference ISO12103-1 (Arizona Road Dust) aerosols with a density of $2.65 \mathrm{mg} \mathrm{m}^{-3}$ and a volumetric mean diameter (VMD) of $2.12 \mu \mathrm{m}$ (Jiang et al. 2011). Measurements were made at a flow of $1.7 \mathrm{~L} \mathrm{~min}^{-1}$ at 10 -s intervals, using the default calibration factor for ambient aerosol 0.38 (Dacunto et al. 2013). Given that the right calibration factor is applied, the AM520 delivers reliable results $\left(R^{2}=0.82\right)$, when compared to reference instruments such as a BAM 1020, Beta Ray Attenuation Monitor 1020, MetOne Instruments (Stauffer et al. 2020). The AM520 was tested during chamber experiments against computed mass concentration from a Scanning Mobility Particle Sizer (SMPS), as described in Vernooij et al. (in prep.) and Vernooij and Winiger (2019). Using the $\mathrm{PM}_{1}$ particle impactor, a linear $R^{2}$ of 0.84 ( $p$-value $\left.<0.001\right)$ was found.

\section{Absorption}

A light-weight aethalometer (MicroAeth® AE51, AethLabs) was used for the measurement of equivalent black carbon (eBC). The aethalometer measures aerosol absorption at $880 \mathrm{~nm}$ on a T60 borosilicate glass-fibre filter with Teflon coating, with a precision of $\pm 0.1 \mu \mathrm{g} \mathrm{m}^{-3}$ (minute average at $150 \mathrm{~mL} \mathrm{~min}^{-1}$ ). Measurements were made at 30-s intervals using a flow of $100 \mathrm{~mL} \mathrm{~min}{ }^{-1}$.

The fidelity of the aethalometer was tested during chamber experiments against a reference instrument, a multi-wavelength aethalometer (AE33, Magee Scientific), as described in Vernooij et al. (in prep.) and Vernooij and Winiger (2019). Good agreement was found at $880 \mathrm{~nm}$ between the two instruments, with a linear $R^{2}$ of 0.95 ( $p$-value $<0.001$ ) at concentrations up to $100 \mu \mathrm{g} \mathrm{m}^{-3}$. A study with several AE51 found mean uncertainty ranges of about $10 \%$ when compared to a stationary Multi-Angle Absorption Photometer (MAAP) (Viana et al. 2015). Hence, the AE51 aethalometer is a reliable and suitable instrument for mobile absorption measurements.

\section{Model}

The hourly $\mathrm{PM}_{2.5}$ model data of January $23^{\text {rd }} 2019$ was downloaded from the open-access platform Atmosphere Data Store of the Copernicus Atmosphere Monitoring Service (CAMS 2020). CAMS is implemented by the European Centre for Medium-Range Weather Forecasts (ECMWF) on behalf of the European Commission. The data was downloaded as ensemble analysis from the available models for that date CHIMERE, EMEP, LOTOS-EUROS, MATCH, MOCAGE, SILAM, and EURAD-IM (DEHM and GEM-AQ data are only available since October $\left.16^{\text {th }} 2019\right)$. The ensemble has a $0.1^{\circ}$ resolution and the values are calculated for each grid from the median of the different model values (Marécal et al. 2015). BC data was not available for January $23^{\text {rd }} 2019$.

This analysis contains modified Copernicus Atmosphere Monitoring Service information 2020; neither the European Commission nor ECMWF is responsible for any use that may be made of the Copernicus information or data it contains.

\section{Reference stations}

Daily averaged $\mathrm{PM}_{2.5}$ data was downloaded from the openaccess platform of the German Environment Agency (UBA 2020b). This database contains air quality data from all official German air quality monitoring stations, belonging to federal and state monitoring networks. Hourly eBC data was kindly provided by the German Environment Agency's Air Quality Assessment unit (II 4.2) upon request. Information on the individual stations can be found on another openaccess platform (UBA 2020a). A selection of the available stations is given in Table 2, i.e. a full list of stations that provided eBC data.

\section{Data analysis}

All data analysis was conducted in python using Jupyter notebooks (Kluyver et al. 2016) and the following packages:

NumPy 1.18.1 (Oliphant 2006), Pandas 1.0.3 (McKinney et al. 2010), Matplotlib 3.1.3 (Hunter 2007), xarray 0.15.1 (Hoyer and Hamman 2017), SciPy 1.4.1 (SciPy 1.0 Contributors et al. 2020), NetCDF4 1.4.2 (NETCDF4 2020), and CDO 1.9.8 (Schulzweida 2019).

GPS data was generated using the android My Tracks app (v1.1) on a Fairphone 2 mobile device. GPS bounce was fixed by removing physically impossible changes in geographical data, removing the few data points leading to train speeds above $400 \mathrm{~km} \mathrm{~h}^{-1}$ (maximum operational ICE train speed is around $300 \mathrm{~km} \mathrm{~h}^{-1}$ ). This GPS dataset was merged with the data from the SidePak ${ }^{\mathrm{TM}}$ AM520 and the MicroAeth® AE51. Missing GPS signal led to several smaller gaps, when projecting the data on a map.

Hourly CAMS $\mathrm{PM}_{2.5}$ was resampled to daily averages with xarray. The anomaly (divergence) between the daily model average and the scattering data of the reference network or TSI SidePak ${ }^{\mathrm{TM}}$ AM520, respectively, was computed using CDO's remapbil and sub functions (Schulzweida 2019).

\section{Results and discussion}

\section{Concentration measurements}

Absorption and scattering observations with the two instruments are arranged in five groups, according to the different 
Table 2 All stations within the network of the German Environment Agency that produced eBC data for January 23, 2019

\begin{tabular}{lllll}
\hline Station code & Station name & Classification & PM $_{2.5}$ instrument & eBC instrument \\
\hline DERP007 & Mainz-Mombach & Urban background & Only PM PAAP $_{10}$ \\
DERP010 & Mainz-Parcusstraße & Urban traffic & Nephelometry and beta attenuation & MAAP \\
DERP041 & Ludwigshafen-Heinigstraße & Urban traffic & "Light scattering" & MAAP \\
DERP045 & Koblenz-Hohenfelder Straße & Urban traffic & Only PM 10 & MAAP \\
DERP046 & Neuwied-Hermannstraße & Urban traffic & Nephelometry and beta attenuation & MAAP \\
DERP047 & Trier-Pfalzel & Suburban industrial & Nephelometry and beta attenuation & MAAP \\
DERP060 & Pirmasens-Innenstadt & Urban background & Only PM & MAAP \\
DEST050 & Halle/Nord & Urban background & Nephelometry and beta attenuation & "light absorption" \\
DEST077 & Magdeburg/West & Urban background & Nephelometry and beta attenuation & "light absorption" \\
DEST089 & Zartau/Waldstation & Rural regional background & Only PM10 & "light absorption" \\
DEST102 & Halle/Paracelsusstr & Urban traffic & "Light scattering" & "light absorption" \\
DEST103 & Magdeburg Schleinufer & Urban traffic & Low volume sampler (gravimetry) & "light absorption" \\
DEUB005 & Waldhof & Rural background & Nephelometry and beta attenuation & MAAP \\
\hline
\end{tabular}

stages of the recorded train journey (Fig. 1). The three different trains are categorized by train type (IC, ICE1, and ICE3; according to Table 1). In addition to those longer train legs are the two city environments in Frankfurt (FRA) and Amsterdam (AMS), measured outside of the trains. Observations at FRA consist only of a 5-min change of trains, including a walk through a pedestrian underpass, and are likely not representative of the city or even the main train station of Frankfurt. The 15-min walk in AMS also only gives a glimpse into the inner-city air quality. In Basel, the connecting trains were on the same platform and the changeover was so fast $(<30 \mathrm{~s})$ that almost no measured data is available.

The $\mathrm{PM}_{2.5}$ measurements revealed that passengers experienced the highest concentrations in the IC (leg 1), with mean concentrations of $58.4 \pm 12.7 \mu \mathrm{g} \mathrm{m}^{-3}$ (1 standard deviation; $\sigma$ ). Mean concentrations decreased in the consecutive train ICE1 (leg 2) to $32.6 \pm 7.2 \mu \mathrm{g} \mathrm{m}^{-3}$, and further to $21.5 \pm 7.3 \mu \mathrm{g} \mathrm{m}^{-3}$ in the final (leg 3 ) train. The two cities showed similar values of $55.3 \pm 15.3 \mu \mathrm{g} \mathrm{m}^{-3}$ (FRA) and $51.9 \pm 9.9 \mu \mathrm{g} \mathrm{m}^{-3}$ (AMS), comparable to the IC train.

The absorption measurements showed a similar pattern to the scattering observations. The highest mean eBC was observed in the IC with $5.4 \pm 2.9 \mu \mathrm{g} \mathrm{m}^{-3}(1 \sigma)$, with consecutively decreasing concentrations in the following ICE1 $\left(1.4 \pm 0.7 \mu \mathrm{g} \mathrm{m}^{-3}\right)$ and ICE3 $\left(0.5 \pm 0.2 \mu \mathrm{g} \mathrm{m}^{-3}\right)$ trains. eBC mass concentrations in FRA were again slightly higher $\left(3.4 \pm 0.3 \mu \mathrm{g} \mathrm{m}^{-3}\right)$ compared to AMS $\left(2.5 \pm 1.7 \mu \mathrm{g} \mathrm{m}^{-3}\right)$.

The eBC and $\mathrm{PM}_{2.5}$ concentration show relatively good linear correlations of $R^{2}=0.73$ ( $p$-value $\left.<0.001\right)$. The respective concentration changes show a very similar pattern over the entire travel distance (Fig. 2). During the first leg from Zürich to Basel, some of the highest values of the entire campaign were frequently recorded for both eBC and $\mathrm{PM}_{2.5}$. Resulting eBC and $\mathrm{PM}_{2.5}$ exposure levels in the IC train were comparable to busy roadsides in an urban
European environment (Karanasiou et al. 2014). At times, a metallic smell could be sensed as a result of braking. It is likely that most of the highest spikes in both eBC and $\mathrm{PM}_{2.5}$ were created through abrasion and other processes during deceleration. There is strong evidence that this was mostly iron oxide (e.g. $\mathrm{Fe}_{2} \mathrm{O}_{3}$ ) (Bukowiecki et al. 2007; Burkhardt et al. 2008). It is also likely that eBC measurements have been particularly influenced by iron and other metal oxides, leading to overestimated eBC readings. The influence of metal oxides could be quantified, if absorption had been measured at more than one wavelength, as metal oxides absorb stronger at lower wavelengths (Alfaro 2004). On the other hand, it has been shown that our particular type of instrument is underestimated by up to $70 \%$, depending on the specific treatment of the filter loading effect (Good et al. 2017). The here presented data are therefore from the direct reading of the instrument, without any corrections. Corrections would only be possible if the measured aerosol would have been monitored with e.g. a multi-wavelength or multispot aethalometer (Drinovec et al. 2015). These sources of uncertainty present a major limitation of the one-wavelength micro-aethalometer measurements. However, the relatively old train type in question is less and less in operation. Most commuters in Switzerland sit in newer carriages nowadays, presumably with better air filtration systems. The metallic smell of the brakes is at least mostly a thing of the past.

No peculiar patterns emerged from the measurements of the second leg in the ICE1. The 5-min change of trains at the end of the second leg at the FRA main station led to increased particle exposure, for both eBC and $\mathrm{PM}_{2.5}$. Observed mean concentrations of $\mathrm{PM}_{2.5}$ were higher than what was found in a comparable study with 30-min measurements during summer in and around FRA main station (Gerber et al. 2014). The difference in observation could be 

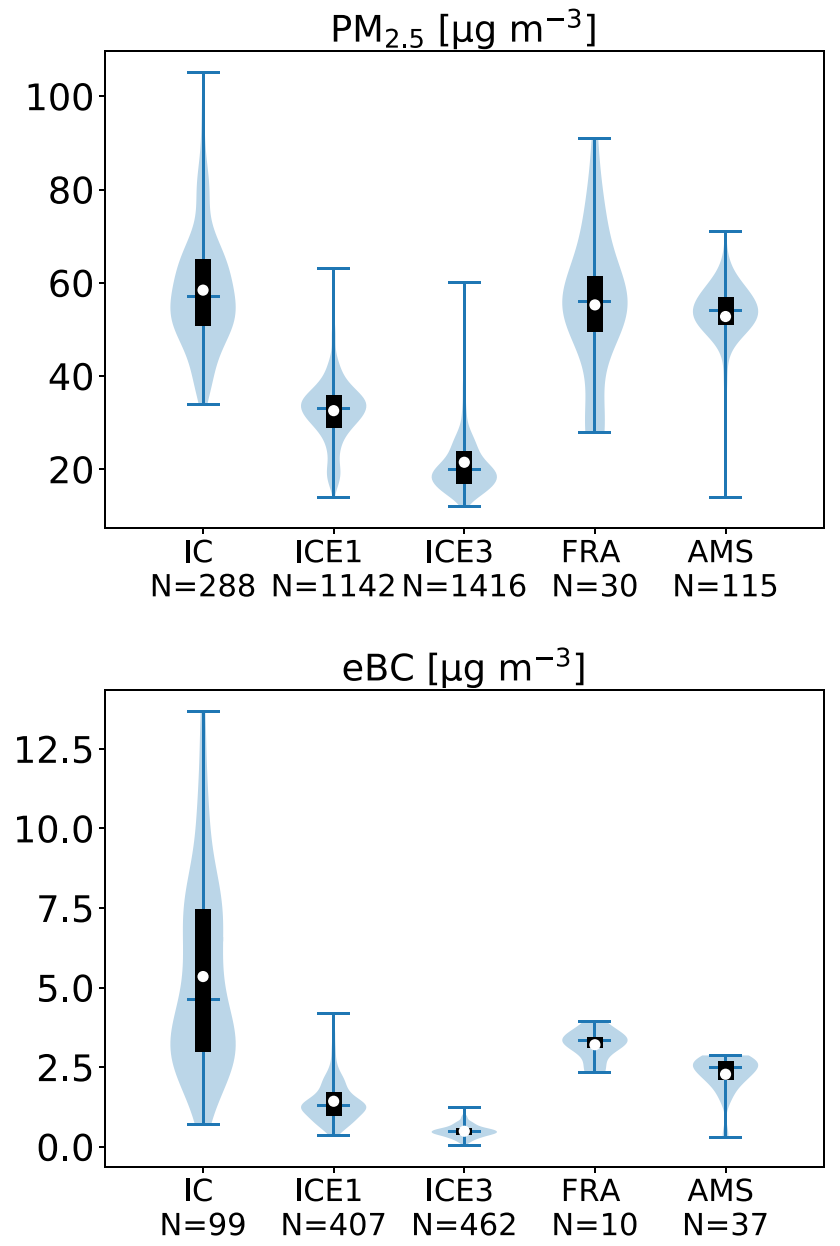

Fig. 1 Violin plots showing the distribution of measurements made for particulate matter $\mathrm{PM}_{2.5}$ (top) and equivalent black carbon eBC (bottom). The top and bottom whiskers show the range of the data. The black box extends from the lower to upper quartile values of the data, with a line at the median. The white point indicates the mean. IC, ICE1, and ICE3 stand for the three different train types of the journey (according to Table 1). FRA and AMS are the cities of Frankfurt and Amsterdam, respectively. Sample size $(N)$ is indicated below the label

due to differences in daily and seasonal particle load (i.e. relatively higher winter vs lower summer concentrations).

On the journey from FRA to AMS, concentration measurements of eBC concentration remained stable. Concentrations of $\mathrm{PM}_{2.5}$, on the other hand, spike right at the Dutch-German border and thereafter slowly decrease to pre-border values (Fig. 3). It is very likely that this is caused by the change of the electric traction system at the border from Germany's $15 \mathrm{kV}_{\mathrm{AC}}$ to the Dutch $1.5 \mathrm{kV}_{\mathrm{DC}}$ (new high-speed lines use $25 \mathrm{kV}_{\mathrm{AC}}$ ). The system change happens via rolling transition, whereby the ICE3 train (previous generations are single voltage only) is detached from the German grid and reconnected to the Dutch grid without ever stopping. The pantograph of the $15 \mathrm{kV}_{\mathrm{AC}}$ transformer retracts from the overhead wire before the 15
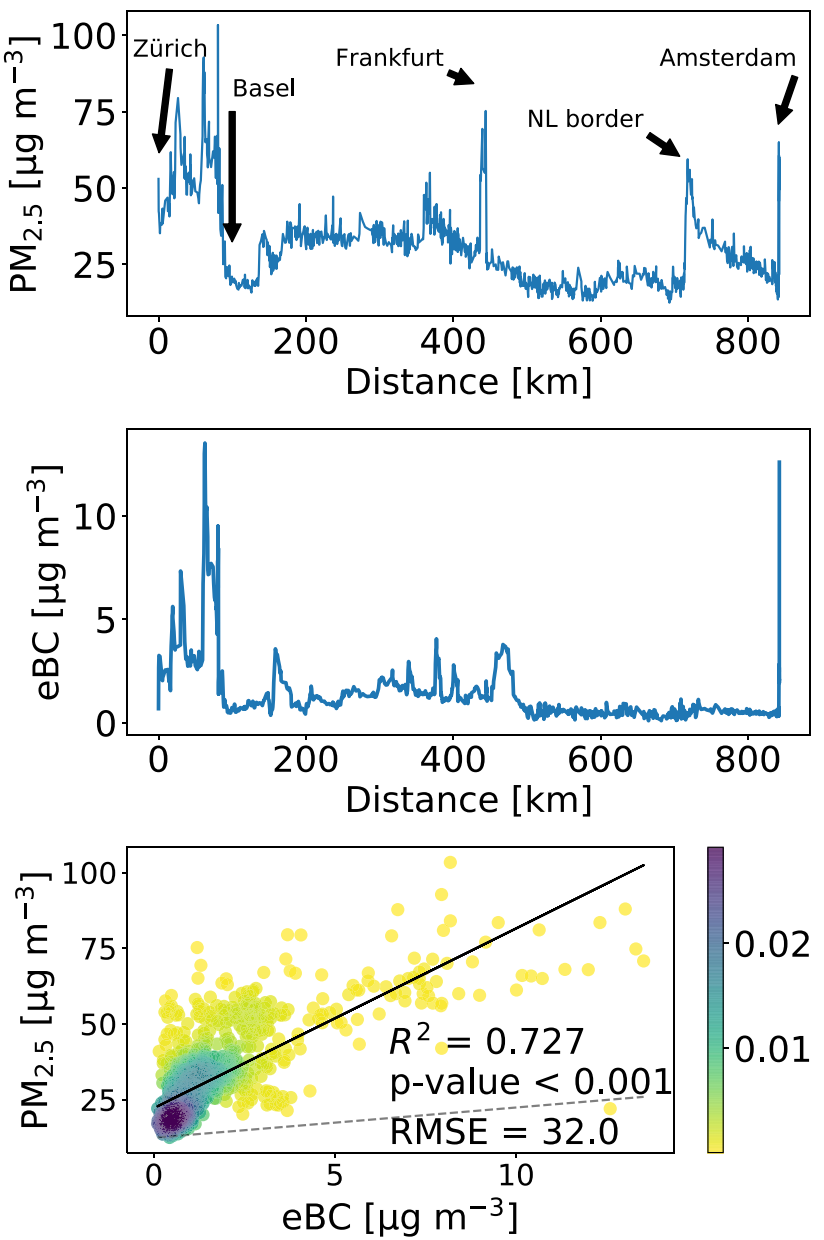

Fig. 2 Particulate matter $\mathrm{PM}_{2.5}$ (top) and equivalent black carbon eBC (middle) concentrations during the entire journey from Zürich to Amsterdam. Note that $\mathrm{eBC}$ is slightly off compared to $\mathrm{PM}_{2.5}$, because of the different sampling interval, short interruptions in measurements, and resulting fit to GPS measurements. Correlation of $\mathrm{PM}_{2.5}$ and eBC (bottom) shows linear $R^{2}$ (black line), $p$-value, and root mean square error (RMSE). The colour code shows observation density fraction and the $1: 1$ ratio (dashed line)

$\mathrm{kV}_{\mathrm{AC}}$ pantograph extends on the other side of the border. In-between this process, there is no current on the train. Active air filtration stops and outside air intrudes unfiltered into the passenger carriage. This border can be classified as rural background, with a strong influence of agriculture, as indicated by the relatively high (hourly) ammonia concentrations simulated by the CAMS model ensemble (for the day of the journey). The CAMS model ensemble showed increased $\mathrm{PM}_{2.5}$ values at the border for 22:00 CET (roughly the time when the train was crossing), from a westward-moving plume over northern Germany (Figure S2). The peak of the plume was upwind of the train tracks. No information on black carbon is available from CAMS, but carbon monoxide concentrations (a proxy for incomplete combustion) were relatively low, showing 
Fig. 3 Geographical view of the particulate matter $\mathrm{PM}_{2.5}$ (left) and equivalent black carbon eBC (right) concentrations during the entire journey from Zürich to Amsterdam. Note the missing data points resulting from the GPS fit

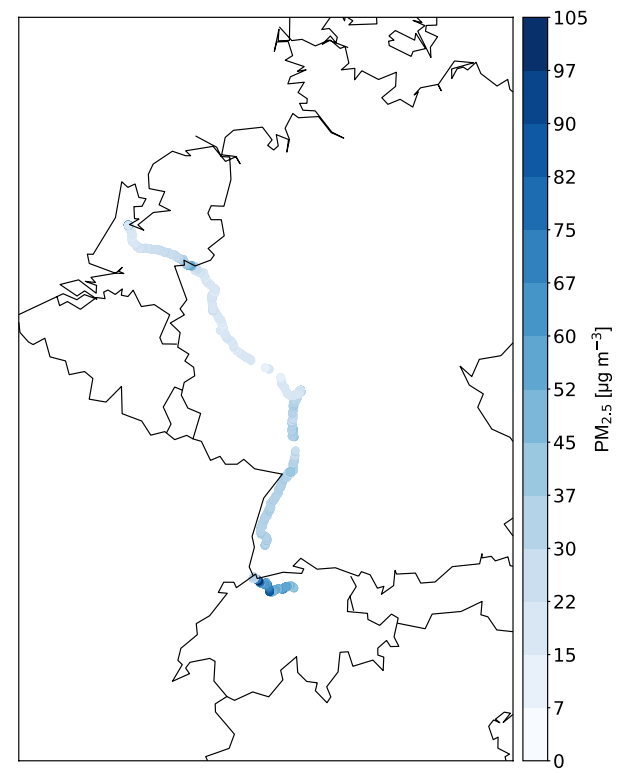

only one big point source further away and downwind of the train tracks.

After disembarking the train in AMS, the observations were continued by foot, walking through a pedestrian underpass and exiting the station on the Eastside. The walk led along a canal towards the East of the inner city, through an area which is largely closed off to taxi traffic (a main source of traffic emissions) after 22 o'clock, walking further eastward. The instruments were switched off right beyond the edge of the low-emission zone (Figure S1). Measurements in city environments show high variations over short distances (Alas et al. 2019; Van den Bossche et al. 2015). The herein presented data is not representative of the general air quality in Amsterdam and functions only as a contrast to the in-train observations.

\section{Analysis of model $\mathrm{PM}_{2.5}$ vs personal aerosol monitor}

As a first reference, the $\mathrm{PM}_{2.5}$ observations made inside the train were compared to the CAMS ensemble analysis (Fig. 4). Therefore, the observations were subtracted from the mean of all hourly model values (i.e. the daily model mean), to give the divergence, hereafter referred to as anomaly. Negative values mean that the model concentrations are lower than the observations. The overall anomaly of the entire journey was $-4.06 \pm 14.4 \mu \mathrm{g} \mathrm{m}^{-3}$
Fig. 4 Comparison of observed to modelled $\mathrm{PM}_{2.5}$. Daily mean model $\mathrm{PM}_{2.5}$ for January $23 \mathrm{rd}$ compared to high-resolution $\mathrm{PM}_{2.5}$ observation (left). The same colour scale applies to both data. Anomaly of observation and model data (right), i.e. divergence of model from observation. Negative values (red) indicate where observations are higher than the model, and vice versa
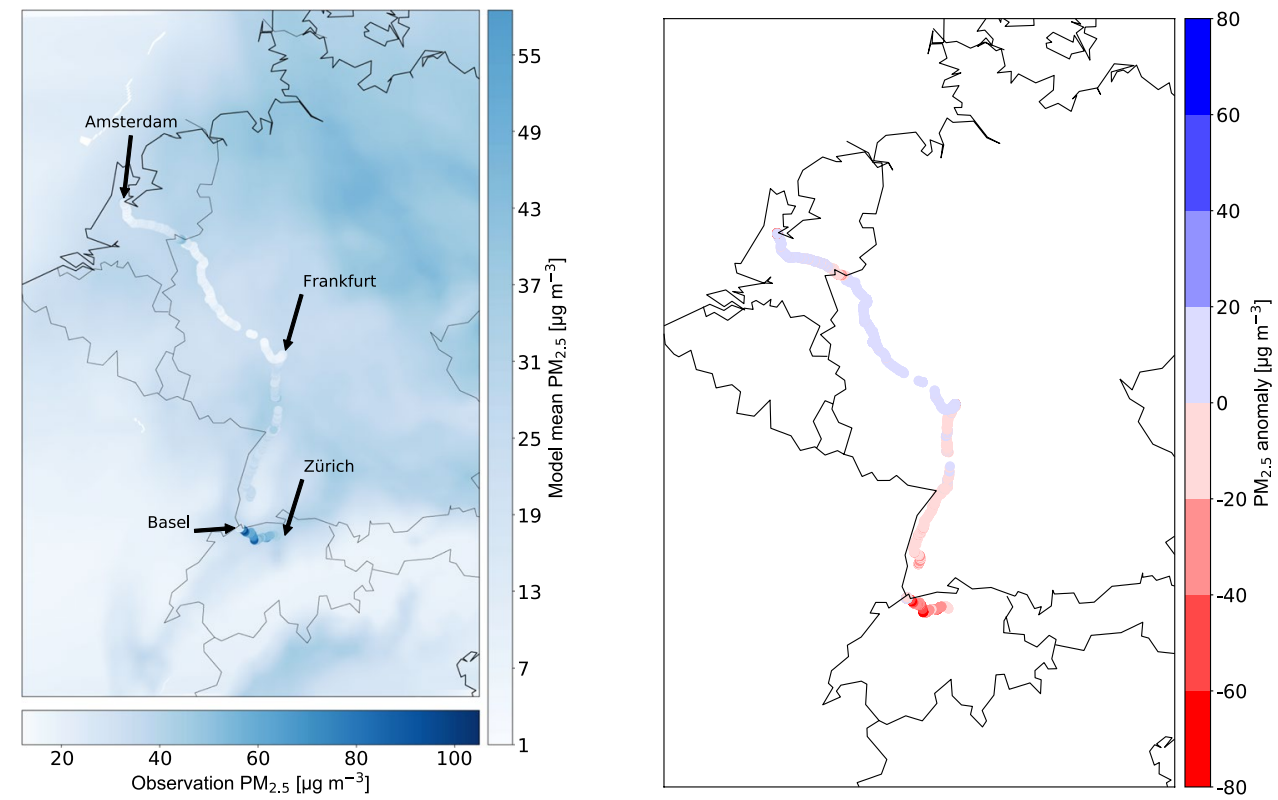
$(1 \sigma)$. For the different train legs, the highest anomaly was found for leg 1 (IC) $-15.0 \pm 19.6 \mu \mathrm{g} \mathrm{m}^{-3}$, followed by leg 2 (ICE1) $-8.6 \pm 7.0 \mu \mathrm{g} \mathrm{m}^{-3}$, and leg 3 $(\mathrm{ICE} 3)+4.9 \pm 7.2 \mu \mathrm{g} \mathrm{m}^{-3}$. The number of measurements in the two different city environments was relatively low; therefore, no anomaly is given. However, these results suggest that at least for half of the journey, specifically inside the ICE3, the air was cleaner than the outside air, whereas during the first leg, inside the old IC, the air was considerably worse than the outside air. The roughly $20 \%$ lower $\mathrm{PM}_{2.5}$ concentration inside the ICE3, compared to CAMS outdoor air, was a result of the air filtration system of this train. According to the French National Railway Company (Société nationale des chemins de fer français, $\mathrm{SNCF}$ ), in modern trains, the entire air volume inside the carriage is replaced with filtered air from outdoors within a few minutes (SNCF 2020). Compared to staying outdoors, the lower aerosol exposure inside the ICE3 should clearly be beneficial to respiratory health. However, proving statistical relevance is difficult. Especially for this study, which only measured one train journey, and offers a limited snapshot only. Using the method by Burnett et al. (2018) to calculate excess mortality due to $\mathrm{PM}_{2.5}$ exposure, it shows that the air inside the most modern train has an attributable mortality fraction that is roughly half as high as that in the oldest train carriage (or the two city environments). The excess mortality due to $\mathrm{PM}_{2.5}$ exposure can be calculated as the product of a country-specific baseline mortality rate and populationattributable mortality fraction. For Western Europe, Burnett et al. (2018) calculate that a $100 \%$ decrease in air pollution would save about 400,000 lives per year. The following calculation makes the big assumption that the concentrations we measured during 1 day would be stable and valid for an entire year, which is of course unrealistic, as indoor and outdoor concentrations likely change substantially over time and space. However, it goes to show what kind of statistical calculations could be performed with all these numbers and underlying assumptions. When applying Burnett et al.'s (2018) method to the train air and normalizing it per German passenger and per hour of train journey, the oldest train carriage leads to a decrease of statistical life expectancy of $\sim 1$ min per hour spent in the old train (or equivalent air quality), compared to the newest studied train system. Although the statistical significance of such a number is questionable, it would be tempting to say that sitting inside a (potentially delayed) ICE3 (and newer generations) would actually extend your life expectancy compared to being outdoors. Whether the decreased aerosol exposure has any influence of potential contagion with infectious diseases would be another very interesting hypothesis to follow up on.

\section{$\mathrm{PM}_{2.5}$ analysis of the model, reference network, and personal aerosol monitor}

The observations and the CAMS ensemble analysis were compared to the monitoring network managed by the German Environment Agency. This network of reference stations spatially spans a large part of the entire journey (Fig. 5). Several stations lie more or less in the vicinity of the passing trains. Without even a quantitative analysis, it is apparent that the air inside of the 3rd leg (ICE3) was much cleaner than the outside air, confirming the first comparison of observations and model ensemble.

Daily averages of both the reference stations and the CAMS ensemble analysis can be subtracted from each other in the same fashion as has been done for the analysis of model $\mathrm{PM}_{2.5}$ and the personal aerosol monitor. This gives an overall anomaly of $-12.2 \pm 7.7 \mu \mathrm{g} \mathrm{m}^{-3}(1 \sigma)$. Anomalies were especially high in German regions where the annual average $\mathrm{PM}_{2.5}$ air pollution is the highest (Lelieveld et al. 2020). This could mean that the air inside the ICE3 train carriage was effectively $>20 \%$ cleaner than outdoors.

\section{eBC reference network vs micro-aethalometer}

Only a few stations monitored $\mathrm{eBC}$ data for the day of the journey (Fig. 5). The mean of each station and the comparison of the closest 5 measurements of leg 2 and leg 3 , respectively, can be found in Table 3. DERP007, an urban background site, had similar values to the eBC of the 2 nd leg. The remaining stations are urban traffic sites, which monitored considerably higher values than observed inside the 2nd leg train. For the 3rd leg, all reference stations had considerably higher values than the micro-aethalometer. Reference measurements were all monitored using MAAP instruments, to which the micro-aethalometer measurements show an uncertainty of only 7 to $12 \%$ (Viana et al. 2015). The differences in measurements are therefore due to other reasons. If we would assume that both observations are conducted in the same open environment, a large part would surely be due to the geographical distance. However, the biggest influence stems from the air filtration system used in the two different generations of ICE trains.

\section{Conclusion}

This limited study shows that the primary factor for the aerosol concentrations and therefore passenger exposure was the type of train carriage, i.e. the applied aerosol filtration system. The newer a train model was, the better its air filtration system compared to the older model. The newest type had even considerably better air quality values than one would expect from outdoor air, whether the outdoor air is measured 
Fig. 5 Comparison of train observation and model data to reference network (all data for same day, $23^{\text {rd }}$ January 2019). The few reference stations with (daily average) eBC data (upper left) are marked with their station code (according to Table 2). Daily average $\mathrm{PM}_{2.5}$ data from all German reference stations (upper right). Observed reference station compared to model data, both daily averages (lower left). The same colour scale applies to both data. Anomaly of reference station and model data (lower right), i.e. divergence of model from observation (both daily averages). Negative values (red) indicate where observations are higher than the model, and vice versa
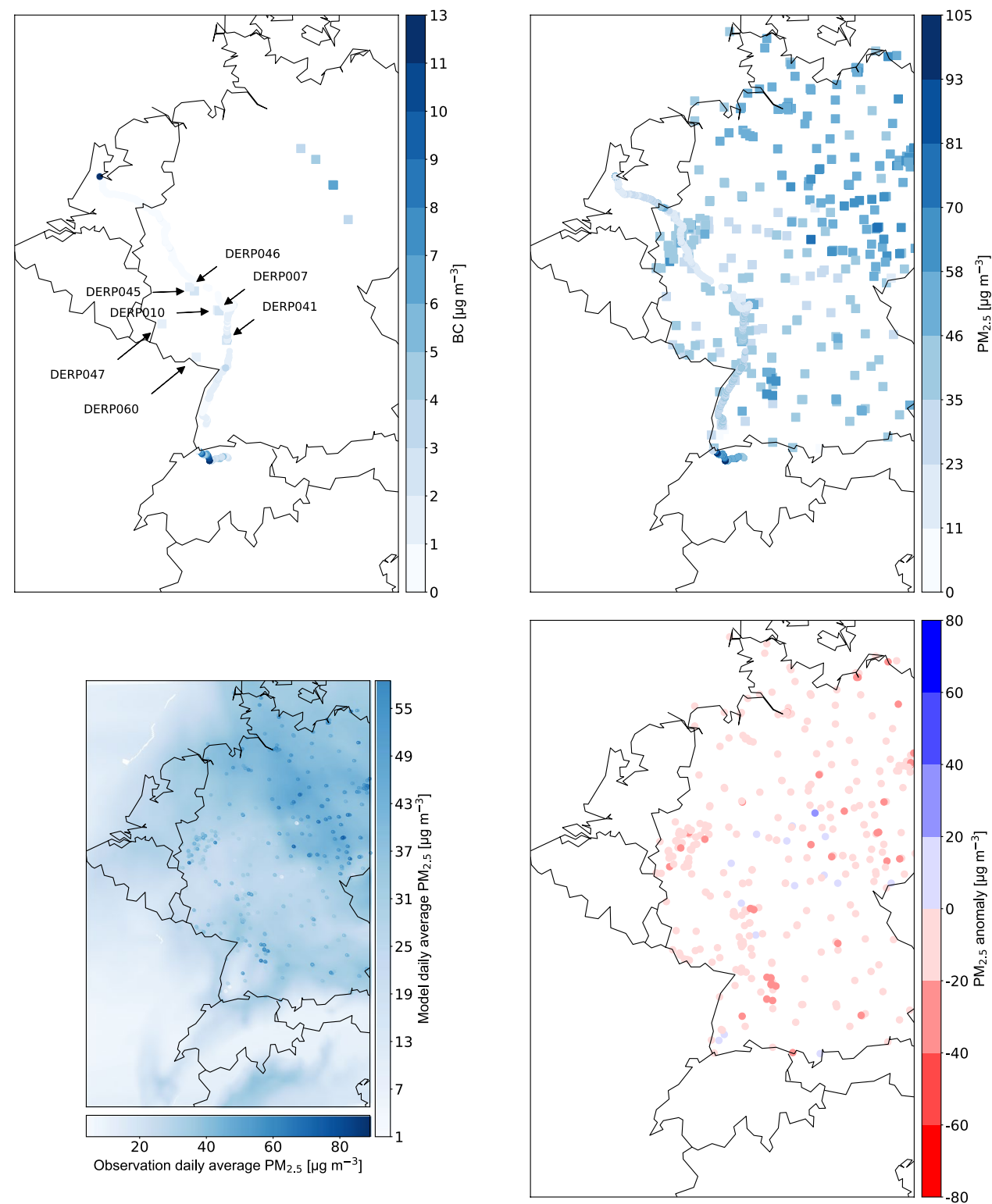

Table $3 \mathrm{eBC}$ values $\left[\mu \mathrm{g} \mathrm{m}^{-3}\right.$ ] from closest 5 train samples to the reference station ( 2 min average $\left.\pm 1 \sigma\right)$

\begin{tabular}{lllllc}
\hline Station & $\begin{array}{l}\text { Station daily mean } \\
\text { eBC }\end{array}$ & $\begin{array}{l}\text { Station hourly eBC leg } \\
\text { 2(time) }\end{array}$ & $\begin{array}{l}\text { Station hourly eBC leg } \\
\text { 3 (time) }\end{array}$ & $\begin{array}{l}\text { Train eBC leg 2 (time) } \\
\text { Train eBC leg 3 (time) }\end{array}$ \\
\hline DERP007 & 1.74 & $1.52(18: 00)$ & $1.51(19: 00)$ & $1.17 \pm 0.14(\sim 18: 00)$ & $0.72 \pm 0.24(\sim 18: 55)$ \\
DERP010 & 2.35 & $2.32(18: 00)$ & $2.53(19: 00)$ & $1.30 \pm 0.07(\sim 18: 00)$ & $0.57 \pm 0.14(\sim 18: 50)$ \\
DERP041 & 2.64 & $3.43(18: 00)$ & - & $1.17 \pm 0.08(\sim 17: 40)$ & - \\
DERP045 & 2.63 & - & $3.21(19: 00)$ & - & $0.55 \pm 0.30(\sim 19: 15)$ \\
DERP046 & 2.14 & - & $2.45(19: 00)$ & - & $0.61 \pm 0.20(\sim 19: 15)$ \\
\hline
\end{tabular}

by a reference network or simulated by ensemble analysis, and despite that the model analysis showed considerably lower $\mathrm{PM}_{2.5}$ mass concentration than the reference network.

Mass transit with a high-quality air filtration system and personal protection measures (e.g. masks) could substantially lower the risk of getting exposed to aerosol concentrations. Refitting older trains with active air filtration has the highest potential of reducing aerosol exposure. Reducing aerosol concentrations in general could even lower the risk of getting infected by diseases that use aerosols as 
a vector to spread through a population. Careful monitoring of cabin air could have additional benefits. This could be by direct aerosol measurements, or by $\mathrm{CO}_{2}$ concentration as a proxy. Absent reporting of infection hotspots from train travel and a preliminary study showing train conductors not being more frequently affected than control groups (Charité 2020) are positive reinforcements for this suggestion. A safer and healthier mass transit would also have additional implications in changing mass mobility, towards a society in line with temperature limits set out by the Paris Agreement.

Supplementary Information The online version contains supplementary material available at https://doi.org/10.1007/s11869-021-01143-2.

Acknowledgements Thank you to Guido van der Werf for lending me the instruments, Roland Vernoji for comments, help, and constructive discussions during the calibration of the instruments, Karin Uhse for station data, Sebastian Brechtel for data analysis support, and Lisa Bröder for ideas and constructive criticism. I thank two anonymous reviewers for constructive comments and suggestions.

Funding Open access funding provided by Swiss Federal Institute of Technology Zurich

Availability of data and material (data transparency) All data is available upon request from the author

Code availability (software application or custom code) All code is available upon request from the author

\section{Declarations}

Competing interests The authors declare no competing interests.

Open Access This article is licensed under a Creative Commons Attribution 4.0 International License, which permits use, sharing, adaptation, distribution and reproduction in any medium or format, as long as you give appropriate credit to the original author(s) and the source, provide a link to the Creative Commons licence, and indicate if changes were made. The images or other third party material in this article are included in the article's Creative Commons licence, unless indicated otherwise in a credit line to the material. If material is not included in the article's Creative Commons licence and your intended use is not permitted by statutory regulation or exceeds the permitted use, you will need to obtain permission directly from the copyright holder. To view a copy of this licence, visit http://creativecommons.org/licenses/by/4.0/.

\section{References}

Abadie M, Limam K, Bouilly J, Génin D (2004) Particle pollution in the French high-speed train (TGV) smoker cars: measurement and prediction of passengers exposure. Atmos Environ 38(14):20172027. https://doi.org/10.1016/j.atmosenv.2004.02.013

Alas HDC, Weinhold K, Costabile F, Di Ianni A, Müller T, Pfeifer S, Di Liberto L, Turner JR, Wiedensohler A (2019) Methodology for high-quality mobile measurement with focus on black carbon and particle mass concentrations. Atmos Meas Tech 12(9):4697-4712. https://doi.org/10.5194/amt-12-4697-2019
Alfaro SC (2004) Iron oxides and light absorption by pure desert dust: an experimental study. J Geophys Res 109(D8):D08208. https:// doi.org/10.1029/2003JD004374

Bukowiecki N, Gehrig R, Hill M, Lienemann P, Zwicky CN, Buchmann B, Weingartner E, Baltensperger U (2007) Iron, manganese and copper emitted by cargo and passenger trains in Zürich (Switzerland): size-segregated mass concentrations in ambient air. Atmos Environ 41(4):878-889. https://doi.org/10.1016/j.atmos env.2006.07.045

Burkhardt M, Rossi L, Boller M (2008) Diffuse release of environmental hazards by railways. Desalination 226(1-3):106-113. https:// doi.org/10.1016/j.desal.2007.02.102

Burnett R, Chen H, Szyszkowicz M, Fann N, Hubbell B, Pope CA, Apte JS, Brauer M, Cohen A, Weichenthal S, Coggins J, Di Q, Brunekreef B, Frostad J, Lim SS, Kan H, Walker KD, Thurston GD, Hayes RB, Lim CC, Turner MC, Jerrett M, Krewski D, Gapstur SM, Diver WR, Ostro B, Goldberg D, Crouse DL, Martin RV, Peters P, Pinault L, Tjepkema M, van Donkelaar A, Villeneuve PJ, Miller AB, Yin P, Zhou M, Wang L, Janssen NAH, Marra M, Atkinson RW, Tsang H, Quoc Thach T, Cannon JB, Allen RT, Hart JE, Laden F, Cesaroni G, Forastiere F, Weinmayr G, Jaensch A, Nagel G, Concin H, Spadaro JV (2018) Global estimates of mortality associated with long-term exposure to outdoor fine particulate matter. Proc Natl Acad Sci USA 115(38):9592-9597. https://doi.org/10.1073/pnas.1803222115

CAMS: Atmosphere Data Store, [online] Available from: https://ads. atmosphere.copernicus.eu/cdsapp\#!/home (Accessed 29 August 2020), 2020

Cepeda M, Schoufour J, Freak-Poli R, Koolhaas CM, Dhana K, Bramer WM, Franco OH (2017) Levels of ambient air pollution according to mode of transport: a systematic review. Lancet Public Health 2(1):e23-e34. https://doi.org/10.1016/S2468-2667(16)30021-4

Charité ROG (2020) Epidemiologische Abklärung am Beispiel COVID-19, Charité Research Organisation GmbH. [online] Available from: https://www.deutschebahn.com/resource/blob/55811 14/836fa701a5b73aa513bc3fdb30419efd/Kurzfassung-StudieCharite-data.pdf (Accessed 12 October 2020)

Cheng Y-H, Liu Z-S, Yan J-W (2012) Comparisons of PM10, PM2.5, particle number, and $\mathrm{CO} 2$ levels inside metro trains between traveling in underground tunnels and on elevated tracks. Aerosol Air Qual Res 12(5):879-891. https://doi.org/10.4209/aaqr.2012.05. 0127

Dacunto PJ, Cheng K-C, Acevedo-Bolton V, Jiang R-T, Klepeis NE, Repace JL, Ott WR, Hildemann LM (2013) Real-time particle monitor calibration factors and PM2.5 emission factors for multiple indoor sources. Environ Sci Processes Impacts 15(8):1511. https://doi.org/10.1039/c3em00209h

Dons E, Int Panis L, Van Poppel M, Theunis J, Wets G (2012) Personal exposure to black carbon in transport microenvironments. Atmos Environ 55:392-398. https://doi.org/10.1016/j.atmosenv. 2012.03.020

Drinovec L, Močnik G, Zotter P, Prévôt ASH, Ruckstuhl C, Coz E, Rupakheti M, Sciare J, Müller T, Wiedensohler A, Hansen ADA (2015) The "dual-spot" Aethalometer: an improved measurement of aerosol black carbon with real-time loading compensation. Atmos Meas Tech 8(5):1965-1979. https://doi.org/10.5194/ amt-8-1965-2015

Fridell E, Björk A, Ferm M, Ekberg A (2011) On-board measurements of particulate matter emissions from a passenger train. Proc IMechE, Part F: J Rail and Rapid Transit 225(1):99-106. https:// doi.org/10.1177/09544097JRRT407

Gerber A, Bohn J, Groneberg DA, Schulze J, Bundschuh M (2014) Airborne particulate matter in public transport: a field study at major intersection points in Frankfurt am Main (Germany). J Occup Med Toxicol 9(1):13. https://doi.org/10.1186/1745-6673-9-13 
Good N, Mölter A, Peel JL, Volckens J (2017) An accurate filter loading correction is essential for assessing personal exposure to black carbon using an aethalometer. J Expo Sci Environ Epidemiol 27(4):409-416. https://doi.org/10.1038/jes.2016.71

Hasenfratz D, Saukh O, Walser C, Hueglin C, Fierz M, Thiele L (2014) Pushing the spatio-temporal resolution limit of urban air pollution maps. 2014 IEEE International Conference on Pervasive Computing and Communications (PerCom). IEEE, Budapest, pp 69-77

Hoyer S, Hamman JJ (2017) xarray: N-D labeled arrays and datasets in Python. J Open Res Softw 5:10. https://doi.org/10.5334/jors.148

Hunter JD (2007) Matplotlib: A 2D graphics environment. Comput Sci Eng 3:90-95

Ivanova D, Wood R (2020) The unequal distribution of household carbon footprints in Europe and its link to sustainability. Glob Sustain 3:e18. https://doi.org/10.1017/sus.2020.12

Jiang R-T, Acevedo-Bolton V, Cheng K-C, Klepeis NE, Ott WR, Hildemann LM (2011) Determination of response of real-time SidePak AM510 monitor to secondhand smoke, other common indoor aerosols, and outdoor aerosol. J Environ Monit 13(6):1695. https://doi.org/10.1039/c0em00732c

Johansson C, Johansson P- $\AA$ (2003) Particulate matter in the underground of Stockholm. Atmos Environ 37(1):3-9. https://doi.org/ 10.1016/S1352-2310(02)00833-6

Kam W, Cheung K, Daher N, Sioutas C (2011) Particulate matter (PM) concentrations in underground and ground-level rail systems of the Los Angeles Metro. Atmos Environ 45(8):1506-1516. https:// doi.org/10.1016/j.atmosenv.2010.12.049

Karanasiou A, Viana M, Querol X, Moreno T, de Leeuw F (2014) Assessment of personal exposure to particulate air pollution during commuting in European cities-recommendations and policy implications. Sci Total Environ 490:785-797. https://doi.org/10. 1016/j.scitotenv.2014.05.036

Kaur S, Nieuwenhuijsen MJ, Colvile RN (2007) Fine particulate matter and carbon monoxide exposure concentrations in urban street transport microenvironments. Atmos Environ 41(23):4781-4810. https://doi.org/10.1016/j.atmosenv.2007.02.002

Kluyver T, Ragan-Kelley B, Pérez F, Bussonnier M, Frederic J, Hamrick J, Grout J, Corlay S, Ivanov P, Abdalla S, Willing C (2016) Jupyter Notebooks-a publishing format for reproducible computational workflows, p. 4. https://eprints.soton.ac.uk/403913/1/ STAL9781614996491-0087.pdf

Lelieveld J, Pozzer A, Pöschl U, Fnais M, Haines A, Münzel T (2020) Loss of life expectancy from air pollution compared to other risk factors: a worldwide perspective. Cardiovasc Res 116(11):19101917. https://doi.org/10.1093/cvr/cvaa025

Leutwyler M, Siegmann K, Monn C (2002) Suspended particulate matter in railway coaches. Atmos Environ 36(1):1-7. https://doi.org/ 10.1016/S1352-2310(01)00487-3

Li T-T, Bai Y-H, Liu Z-R, Li J-L (2007) In-train air quality assessment of the railway transit system in Beijing: a note. Transp Res Part d: Transp Environ 12(1):64-67. https://doi.org/10.1016/j.trd.2006. 11.001

Marécal V, Peuch V-H, Andersson C, Andersson S, Arteta J, Beekmann M, Benedictow A, Bergström R, Bessagnet B, Cansado A, Chéroux F, Colette A, Coman A, Curier RL, Denier van der Gon HAC, Drouin A, Elbern H, Emili E, Engelen RJ, Eskes HJ, Foret G, Friese E, Gauss M, Giannaros C, Guth J, Joly M, Jaumouillé E, Josse B, Kadygrov N, Kaiser JW, Krajsek K, Kuenen J, Kumar U, Liora N, Lopez E, Malherbe L, Martinez I, Melas D, Meleux F, Menut L, Moinat P, Morales T, Parmentier J, Piacentini A, Plu M, Poupkou A, Queguiner S, Robertson L, Rouïl L, Schaap M, Segers A, Sofiev M, Tarasson L, Thomas M, Timmermans R, Valdebenito Á, van Velthoven P, van Versendaal R, Vira J, Ung A (2015) A regional air quality forecasting system over Europe: the MACCII daily ensemble production. Geosci Model Dev 8(9):2777-2813. https://doi.org/10.5194/gmd-8-2777-2015
McKinney W et al. (2010) Data structures for statistical computing in python, in In Proceedings of the 9th Python in Science Conference, pp. 51-56. http://conference.scipy.org/proceedings/scipy 2010/pdfs/mckinney.pdf

Morales Betancourt R, Galvis B, Balachandran S, Ramos-Bonilla JP, Sarmiento OL, Gallo-Murcia SM, Contreras Y (2017) Exposure to fine particulate, black carbon, and particle number concentration in transportation microenvironments. Atmos Environ 157:135145. https://doi.org/10.1016/j.atmosenv.2017.03.006

Morawska L, Tang JW, Bahnfleth W, Bluyssen PM, Boerstra A, Buonanno G, Cao J, Dancer S, Floto A, Franchimon F, Haworth C, Hogeling J, Isaxon C, Jimenez JL, Kurnitski J, Li Y, Loomans M, Marks G, Marr LC, Mazzarella L, Melikov AK, Miller S, Milton DK, Nazaroff W, Nielsen PV, Noakes C, Peccia J, Querol X, Sekhar C, Seppänen O, Tanabe S, Tellier R, Tham KW, Wargocki P, Wierzbicka A, Yao M (2020) How can airborne transmission of COVID-19 indoors be minimised? Environ Int 142:105832. https://doi.org/10.1016/j.envint.2020.105832

NETCDF4 (2020) Unidata/netcdf4-python, Python, Unidata. [online] Available from: https://github.com/Unidata/netcdf4-python (Accessed 29 August 2020)

Oliphant TE (2006) A guide to NumPy, Trelgol Publishing USA. https://www.nature.com/articles/s41586-020-2649-2

Prather KA, Marr LC, Schooley RT, McDiarmid MA, Wilson ME, Milton DK (2020) Airborne transmission of SARS-CoV-2. Science 370:303-304, https://doi.org/10.1126/science.abf0521

Ragettli MS, Corradi E, Braun-Fahrländer C, Schindler C, de Nazelle A, Jerrett M, Ducret-Stich RE, Künzli N, Phuleria HC (2013) Commuter exposure to ultrafine particles in different urban locations, transportation modes and routes. Atmos Environ 77:376384. https://doi.org/10.1016/j.atmosenv.2013.05.003

Schulzweida U (2019) CDO User Guide (Version 1.9.8), https://doi. org/10.5281/zenodo.3539275

SciPy 1.0 Contributors, Virtanen P, Gommers R, Oliphant TE, Haberland M, Reddy T, Cournapeau D, Burovski E, Peterson P, Weckesser W, Bright J, van der Walt SJ, Brett M, Wilson J, Millman KJ, Mayorov N, Nelson ARJ, Jones E, Kern R, Larson E, Carey CJ, Polat I, Feng Y, Moore EW, VanderPlas J, Laxalde D, Perktold J, Cimrman R, Henriksen I, Quintero EA, Harris CR, Archibald AM, Ribeiro AH, Pedregosa F, van Mulbregt P (2020) SciPy 1.0: fundamental algorithms for scientific computing in Python. Nat Methods 17(3):261-272. https://doi.org/10.1038/ s41592-019-0686-2

Smith JD, Barratt BM, Fuller GW, Kelly FJ, Loxham M, Nicolosi E, Priestman M, Tremper AH, Green DC (2020) PM2.5 on the London Underground. Environ Int 134:105188. https://doi.org/10. 1016/j.envint.2019.105188

SNCF (2020) Covid-19 and air conditioning, SNCF [online] Available from: https://www.sncf.com/en/passenger-offer/travel-by-train/ covid-19-and-air-conditioning (Accessed 12 October 2020)

Stauffer DA, Autenrieth DA, Hart JF, Capoccia S (2020) Control of wildfire-sourced PM2.5 in an office setting using a commercially available portable air cleaner. J Occup Environ Hyg 17(4):109120. https://doi.org/10.1080/15459624.2020.1722314

UBA (2020) Stationsdatenbank: Luftmessstationen in Deutschland, [online] Available from: https://www.env-it.de/stationen/public/ open.do (Accessed 29 August 2020a)

UBA (2020) Umweltbundesamt, Umweltbundesamt [online] Available from: https://www.umweltbundesamt.de/daten/luft/luftdaten/stati onen (Accessed 29 August 2020b)

Van den Bossche J, Peters J, Verwaeren J, Botteldooren D, Theunis J, De Baets B (2015) Mobile monitoring for mapping spatial variation in urban air quality: development and validation of a methodology based on an extensive dataset. Atmos Environ 105:148-161. https://doi.org/10.1016/j.atmosenv.2015.01.017 
Van Ryswyk K, Anastasopolos AT, Evans G, Sun L, Sabaliauskas K, Kulka R, Wallace L, Weichenthal S (2017) Metro commuter exposures to particulate air pollution and $\mathrm{PM}_{2.5}$-associated elements in three Canadian cities: the Urban Transportation Exposure Study. Environ Sci Technol 51(10):5713-5720. https://doi.org/ 10.1021/acs.est.6b05775

Vernooij R and Winiger P (2019) LOW-weight Aerosol Monitoring Evaluation CHAMber exPeriment (LOWAMECHAMP), TNA User Report. [online] Available from: https://www.eurochamp. org/Portals/55/Project/Documentation/TNA\%20documents/ User-scientific\%20reports/LEAK-LACIS-005\%20report_20190 612pw_small.pdf?ver=2019-06-14-140437-917 (Accessed 31 August 2020)

Vernooij R, Winiger P, Strydom T, Poulain L, Dusek U, Wooster M and van der Werf GR. (in prep)

Viana M, Rivas I, Reche C, Fonseca AS, Pérez N, Querol X, Alastuey A, Álvarez-Pedrerol M, Sunyer J (2015) Field comparison of portable and stationary instruments for outdoor urban air exposure assessments. Atmos Environ 123:220-228. https://doi.org/10. 1016/j.atmosenv.2015.10.076

Vilcassim MJR, Thurston GD, Peltier RE, Gordon T (2014) Black carbon and particulate matter $\left(\mathrm{PM}_{25}\right)$ concentrations in New York City's subway stations. Environ Sci Technol 48(24):14738-14745. https://doi.org/10.1021/es504295h

Yang F, Kaul D, Wong KC, Westerdahl D, Sun L, Ho K, Tian L, Brimblecombe P, Ning Z (2015) Heterogeneity of passenger exposure to air pollutants in public transport microenvironments. Atmos Environ 109:42-51. https://doi.org/10.1016/j.atmosenv.2015.03. 009

Publisher's note Springer Nature remains neutral with regard to jurisdictional claims in published maps and institutional affiliations. 